\title{
Distribution Performance Analysis and Experimental Research on the Port Plate Pairs of Low Speed High Torque Seawater Hydraulic Motor
}

\author{
Zhiqiang Wang ${ }^{1,2,3^{*}}$, Shaofeng Wu' ${ }^{1}$, Dianrong Gao ${ }^{4}$ and Shuncai Wang ${ }^{3}$
}

\begin{abstract}
The current research of seawater hydraulic motor mainly focused on piston motor and vane motor, but seldom regarded low speed high torque seawater hydraulic motor. Low speed high torque seawater hydraulic motor as a kind of energy conversion device and actuator plays an important role in seawater hydraulic transmission system. However, the physical and chemical properties of seawater, such as low viscosity, high causticity and poor lubrication, result in numerous problems. In this paper, the flow distribution characteristics of port plate pairs for the seawater hydraulic motor are investigated, and the leakage flow and power loss models of port plate pairs are established. Numerical simulations are carried out to examine the effects of water film, inlet pressure and rotating speed on the pressure distribution and leakage flow. And the friction and wear tests of port plate pairs are also carried out. Moreover, the test system of the seawater hydraulic motor is constructed and the performance of prototype with no-load or loading is conducted. The results indicate that the clearance of port plate pairs and inlet pressure have a significant effect on distribution characteristics, but the effect of rotating speed is not very obvious. The experimental results show that the minimum error rate can be maintained within $0.3 \%$ by the proposed flow model and the counter materials of 316L against carbon-fiber-reinforced polyetheretherketone (CFRPEEK) are suitable for the port plate pairs of seawater hydraulic motor. Finally, based on the seawater hydraulic experiment platform, the volumetric efficiency of no-load and loading are obtained that the maximum can achieve $94.71 \%$ and $90.14 \%$, respectively. This research work may improve the flow distribution performance, lubrication and the friction and wear properties, enhance energy converting efficiency of port plate pair and provide theoretical and technical support for the design of highperformance water hydraulic components.
\end{abstract}

Keywords: Seawater hydraulic motor, Port plate pairs, Leakage flow, Clearance, Numerical simulation, Friction and wear

\section{Introduction}

With the development of industry and population expansion, the problems of resource shortage and environment pollution become more and more serious. Marine exploitation is the primary means of expanding human living

\footnotetext{
*Correspondence: wzq78452501@163.com

1 School of Mechanical Engineering, Hangzhou Dianzi University,

Hangzhou 310018, China

Full list of author information is available at the end of the article
}

space and facilitating the further development. These also promote the development of marine equipments. Due to the advantages of safety, green, no pollution, the natural seawater has become the most popular hydraulic transmission system medium used for the marine equipments [1-4]. Seawater hydraulic motor, as one kind of energy conversion and executive device, also plays an important role in seawater hydraulic system. However, the physical and chemical properties of seawater, such as low viscosity, 
high causticity and vapor pressure, bad frictional property, low resistance and poor lubrication, result in numerous problems. These include friction and wear of friction pairs, corrosion of equipment parts, leakage and efficiency, cavitation and water impulsion, and so on [5-7]. Consequently, the structure design of key friction pairs, material selection and flow distribution research become extremely important for seawater hydraulic components.

In order to solve these problems, international scholars and institutions make lots of research on the seawater hydraulic motor. The Naval Civil Engineering Laboratory in the USA developed an experimental seawater hydraulic tool system, which included a reversible vane motor and unidirectional vane motor for meeting the requirement of deep-ocean exploitation and underwater operations [8]. Thereafter, the multi function tool system was developed, and the driver installation of the system is a seawater hydraulic motor $[9,10]$. In 1988, the British navy collaborated with the Fenner Company developed a series of seawater hydraulic tools which included a seawater hydraulic axial piston motor with the pressure of $10 \mathrm{MPa}$ and maximum rotation speed of $3000 \mathrm{r} / \mathrm{min}$ [11]. In 1994, Danish Danfoss developed the first generation product-water axial piston motor [12]. In 1997, this corporation developed bi-directional tap water hydraulic motor [13]. Then, in 2005, a high pressure system, using four different displace seawater hydraulic axial piston motors and pumps for energy recovery system had been tested [14].

The study of water hydraulic transmission technique began also early in the enterprises of Germany, such as the Hauhinco, SPECK, KAMAT, and so on. Among them, Hauhinco worked on the development and production of water hydraulic components and systems which has been extensively used in the marine equipments $[15,16]$. As an island country, Japan has paid much attention to the exploitation and utilization of marine resources. From 1980s in the last century, a number of corporations and institutions work in water hydraulic transmission and make a lot of research results $[17,18]$. In 1999, a balanced vane type water hydraulic motor was developed with the maximum pressure at $2.0 \mathrm{MPa}$ and the maximal rotational speed at $1500 \mathrm{r} / \mathrm{min}$ in Ebara Research Co., Ltd. However, the mechanical and volumetric efficiencies were low, which were $78 \%$ and $55 \%$, respectively [19].

The present study on water hydraulic motor mainly focused on academic institutions. Oshima et al. [20] reported a low pressure water hydraulic planetary gear motor, and investigated the planetary gears with solid lubricant film, PEEK and brass. The results indicated that the Graphite made the output torque efficiency increase about $15 \%$ and the PEEK also gave a pretty good improvement in the output torque. Wang and Liang [2123] researched the wear and lubrication performance of water-lubricated thrust bearings, and found that the bearings are affected with the different rotary speed and load and proposed some models for studying lubrication performance, which can provide theory support for the optimization design of the water-lubricated bearing. Pham et al. $[24,25]$ researched the feasibility of controlling the performances of a water hydraulic servo motor by changing the angle and velocity with a simple adaptive control, discovered that this method could highly attenuate the effects of disturbances. Meanwhile, they designed a novel water hydraulic transmission technique to improve the efficiency of motor systems. Väyrynen and Aha $[26,27]$ tested the performance of servo valve within water hydraulic systems in high temperatures, the result shown that the pressure of the servo valve gain decreased and hysteresis increased which are both remained within the allowable limits and did not have significant effect on the joint angle tracking error. Kim et al. [28] presented a small reverse osmosis desalination system equipped with a water hydraulic axial piston motor, and measured the separation efficiency and energy consumption of the separation column under $120 \mathrm{~kg} / \mathrm{h}$ fresh water production. Nie et al. [29-32] studied swash-plate water hydraulic axial piston pump, motor and some key technical problems were solved by analyzing the tribological performance of hydrostatic slipper bearing with annular orifice damper, structure design and torque characteristics of the pump and motor. Lu et al. [33] investigated the hydraulic performance and energy consumption of a small reverse osmosis system, and demonstrated that the improvement of volumetric efficiencies of the water hydraulic pump and motor was the main factor to increase the prototype pump performance. Liu et al. [34-36] researched and developed the seawater hydraulic system and components. Meanwhile, in order to improve the control performance and reduce the energy consumption of the water hydraulic system, they proposed a new control method and found that the mean tracing error can be controlled in $0.27 \%$ by this method.

In recent years, the researchers study on the seawater hydraulic motor mainly focused on piston motor and vane motor, but seldom regarded low speed high torque seawater hydraulic motor. This paper conducts the distribution performance analysis and experiments of the port plate pairs in low speed high torque seawater hydraulic motor. In our work, a mathematical model for elaborating the flow and power characteristic of port plate pairs was established. And in order to further investigate the effect of water film, inlet pressure and rotating speed on the leakage flow and pressure distribution of port plate pairs, a CFD numerical simulation model was built up. Then, the friction and wear tests of the counter materials for the port plate pairs were carried out and the leakage flow 

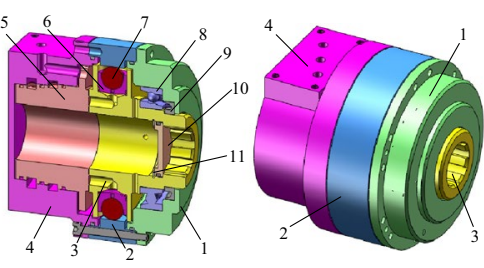

Figure 1 Structure of seawater hydraulic motor with low speed high torque. 1. Front end housing; 2 . Stator; 3. Rotor; 4. Rear housing; 5. Port plate; 6. Plunger; 7. Roller; 8. Bearing; 9. Seal ring; 10. Baffle plate; 11. Jump ring
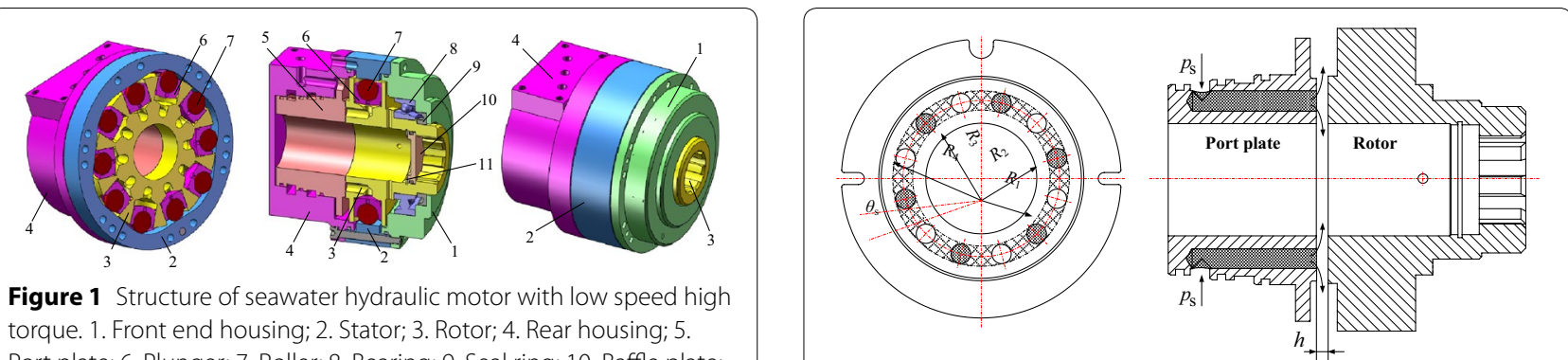

Figure 2 Structure and distribution of port plate in seawater hydraulic motor

$$
p=\frac{6 \mu Q}{\pi h^{3}} \ln \left(R_{i} / R\right)
$$

where $p$ is the pressure of port plate pairs, $\mu$ is kinetic viscosity of water, $Q$ is the leakage flow, $h$ is clearance of port plate, $R_{i}$ is outer ring radius of seal belt, $R$ is the radius in an arbitrary place on seal belt, $R_{i}$ is the radius in an arbitrary place on seal belt and $R$ is inner ring radius of seal belt when calculating the pressure of inner seal belt.

Substituting $r=R_{2}, p_{2}=p_{\mathrm{s}}$ and $r=R_{3}, p_{3}=p_{\mathrm{s}}$ into Eq. (1) can get the leakage flow of inner seal belt and outer seal belt. Thus

$$
Q=\frac{\pi h^{3} p_{s}}{6 \mu}\left(\frac{1}{\ln R_{4} / R_{3}}+\frac{1}{\ln R_{2} / R_{1}}\right),
$$

of rotor, which connected to the piston bores of rotor piston bores of rotor. When the high pressure water flow into each chamber of the piston, the rollers are forced to the inner surfaces of the stator. Then, a normal reaction force acted on the inner surface of the stator, which can be decomposed into two branch forces: a radial branch force and a tangent branch force. The tangent branch force develops a torque at output shaft through the pistons, makes the rotor rotate the output shaft, and forms a certain speed and torque on the output shaft.

\section{Flow and Power Characteristic of Port Plate Pairs 3.1 Modeling of Leakage Flow}

Figure 2 shows the structure and distribution of port plate. As shown in the figure, there are ten piston bores in the rotor which are matched with twelve cylindrical holes in the port plate. The high pressure water is extracted from the port plate, and then the water flows into the holes of rotor. However, a little water flows out from the clearance of port plate and rotor. This is the leakage flow of port plate pairs.

In view of the small clearance of port plate pairs, the movement of fluid in port plate and rotor is treated as a laminar flow in parallel plate clearance [37]. So the pressure distribution rule of port plate can be obtained where $p_{\mathrm{s}}$ is supply pressure, $R_{1}$ is inner ring radius of inner seal belt, $R_{2}$ is outer ring radius of inner seal belt, $R_{3}$ is inner ring radius of outer seal belt, $R_{4}$ is outer ring radius of outer seal belt.

The flow distribution pattern of seawater hydraulic motor is based on the intermittent water supplier of multiple independent flow distribution chambers. Therefore, there are six holes are high pressure and six holes are low pressure, which are switched between high and low pressures. According to the flow distribution pattern mentioned in literature [37], the distribution efficiency can be equivalent to the ratio of the sum of distributor opening area in high pressure and the annular area. Therefore, the leakage correction factor of distributor opening may be rewritten

$$
k_{1}=\frac{6 r_{1}^{2}}{R_{3}^{2}-R_{2}^{2}},
$$

where $r_{1}$ is radius of distributor opening.

Meanwhile, five of ten rotor holes are connected to the flow channel of port plate, so the leakage is very little. Thus, the leakage correction factor of rotor holes may be rewritten 
Table 1 Design parameters of port plate pairs

\begin{tabular}{|c|c|c|c|c|c|}
\hline \multirow{2}{*}{$\begin{array}{l}\text { Distributor } \\
\text { opening } \\
r_{1}(\mathrm{~mm})\end{array}$} & \multirow{2}{*}{$\begin{array}{l}\text { Rotor holes } \\
r_{2}(\mathrm{~mm})\end{array}$} & \multicolumn{2}{|c|}{$\begin{array}{l}\text { Inner ring of seal } \\
\text { belt }\end{array}$} & \multicolumn{2}{|c|}{$\begin{array}{l}\text { Outer ring of seal } \\
\text { belt }\end{array}$} \\
\hline & & $R_{1}(\mathrm{~mm})$ & $R_{2}(\mathrm{~mm})$ & $R_{3}(\mathrm{~mm})$ & $R_{4}(\mathrm{~mm})$ \\
\hline & 8 & 23 & 28.5 & 36.5 & 41.5 \\
\hline
\end{tabular}

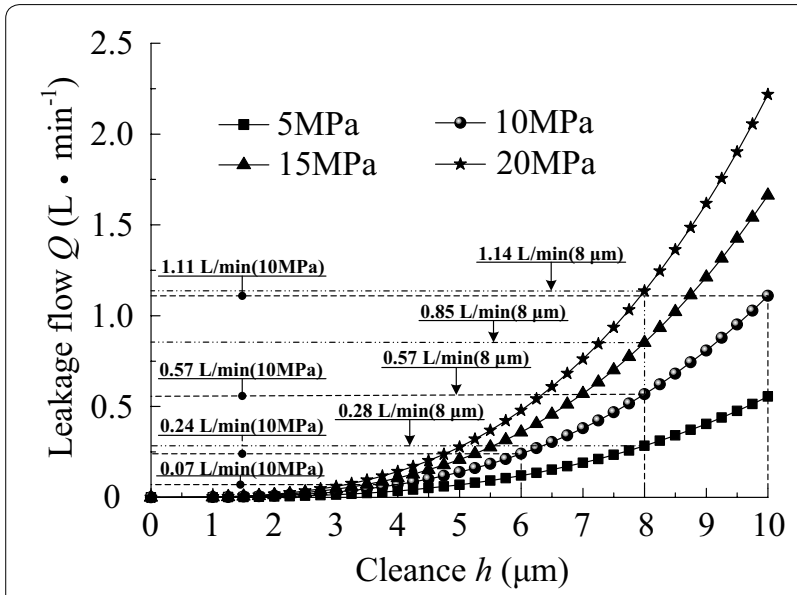

Figure 3 Change of leakage flow with clearance

$$
k_{2}=\frac{R_{3}^{2}-R_{2}^{2}-5 r_{2}^{2}}{R_{3}^{2}-R_{2}^{2}},
$$

where $r_{2}$ is radius of rotor holes.

Assuming that the leakage correction factor of seal belt may be represented by $k_{3}$, then

$$
k_{3}=\frac{1}{\ln R_{4} / R_{3}}+\frac{1}{\ln R_{2} / R_{1}} .
$$

Then from these equations, the leakage flow of port plate pairs can be written

$$
Q_{\mathrm{p}}=\frac{\pi h^{3} p_{s}}{6 \mu} k_{1} k_{2} k_{3},
$$

where $k_{1}, k_{2}$ and $k_{3}$ are the leakage correction factor of distributor opening, rotor holes and seal belt, respectively. Table 1 lists the parameter values of port plate pairs.

Substituting available data into Eq. (6), can get the total leakage flow of port plate pairs. And the change of leakage flow with clearance is shown in Figure 3.

From Figure 3, it can be seen that the leakage flow will increase with the increase of clearance. When the pressure of motor is $10 \mathrm{MPa}$, the leakage flow of port plate pairs are $0.07 \mathrm{~L} / \mathrm{min}(4 \mu \mathrm{m}), 0.24 \mathrm{~L} / \min (6 \mu \mathrm{m}), 0.57 \mathrm{~L} /$ $\min (8 \mu \mathrm{m})$ and $1.11 \mathrm{~L} / \mathrm{min}(10 \mu \mathrm{m})$, respectively. When the clearance of port plate pairs is $8 \mu \mathrm{m}$, the leakage flow are $0.28 \mathrm{~L} / \mathrm{min}(5 \mathrm{MPa}), 0.57 \mathrm{~L} / \mathrm{min}(10 \mathrm{MPa}), 0.85 \mathrm{~L} / \mathrm{min}$ $(15 \mathrm{MPa})$ and $1.14 \mathrm{~L} / \mathrm{min}(20 \mathrm{MPa})$, respectively.

\subsection{Analysis of Power and Water Film Thickness}

Through the modeling of leakage flow, the clearance of port plate pairs has the biggest effect on leakage flow of seawater hydraulic motor. When the total power loss of port plate pairs is minimal, the water film has the best thickness. Meanwhile, the total power loss of port plate pairs includes leakage power loss and frictional power loss of water film.

Since the shear action of water film during the rotation of rotor, the water need to overcome viscous resistance when it flow out of the clearance. Via an infinitesimal method, the frictional power loss of water film can be solved.

$$
\begin{aligned}
N_{f} & =\mu A \frac{U^{2}}{h}=\int_{R_{3}}^{R_{4}} \frac{8 \pi^{3} n^{2} r^{3} \mu}{h} \mathrm{~d} r+\int_{R_{1}}^{R_{2}} \frac{8 \pi^{3} n^{2} r^{3} \mu}{h} \mathrm{~d} r \\
& =\frac{2 \pi^{3} n^{2} \mu\left(R_{4}^{4}-R_{3}^{4}+R_{2}^{4}-R_{1}^{4}\right)}{h},
\end{aligned}
$$

where $A$ is bearing area of friction pairs, $U$ is the sliding speed of the bearing surface for friction pairs and $n$ is the rotating speed of rotor.

Leakage power loss of port plate pairs is caused mainly by the leakage of high pressure fluid. Thus

$$
N_{q}=\frac{\pi \alpha p_{s}^{2} h^{3}}{6 \mu} k_{1} k_{2} k_{3}
$$

where $\alpha$ is the internal pressure drop coefficient.

Combining Eqs. (7) and (8), the equation of total power loss is expressed by

$$
\begin{aligned}
N_{\mathrm{t}} & =N_{f}+N_{q} \\
& =\frac{2 \pi^{3} n^{2} \mu\left(R_{4}^{4}-R_{3}^{4}+R_{2}^{4}-R_{1}^{4}\right)}{h}+\frac{\pi \alpha p_{s}^{2} h^{3}}{6 \mu} k_{1} k_{2} k_{3} .
\end{aligned}
$$

Based on extremal theorem, the partial derivative of $h$ is worked out from Eq. (9). And the optimum water thickness will be

$$
h=\left(\frac{2 \pi n \mu}{p_{s}}\right)^{\frac{1}{2}}\left(\frac{R_{4}^{4}-R_{3}^{4}+R_{2}^{4}-R_{1}^{4}}{\alpha k_{1} k_{2} k_{3}}\right)^{\frac{1}{4}} .
$$

Substituting the data of Table 1 into Eqs. (7) and (8) can get the friction power loss and leakage power loss of port plate, respectively. And the relations of clearance with friction power loss at different rotating speeds and 


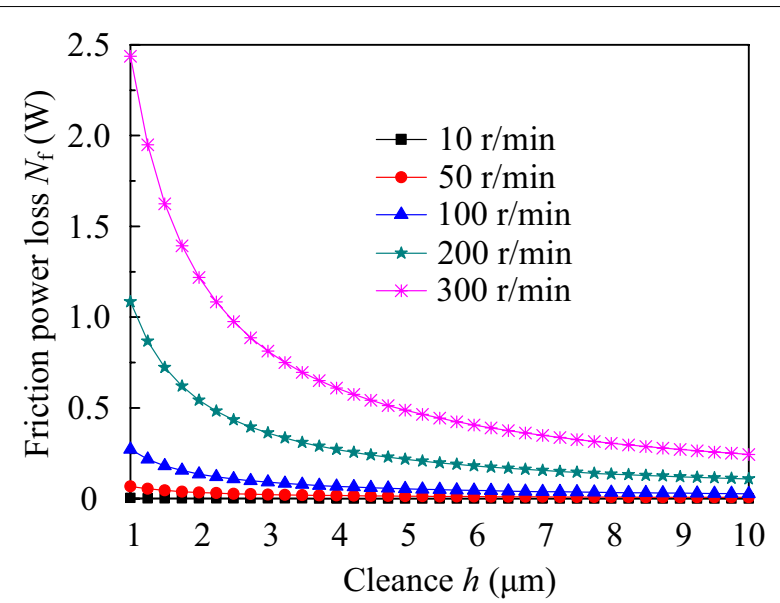

Figure 4 Change of friction power loss with clearance

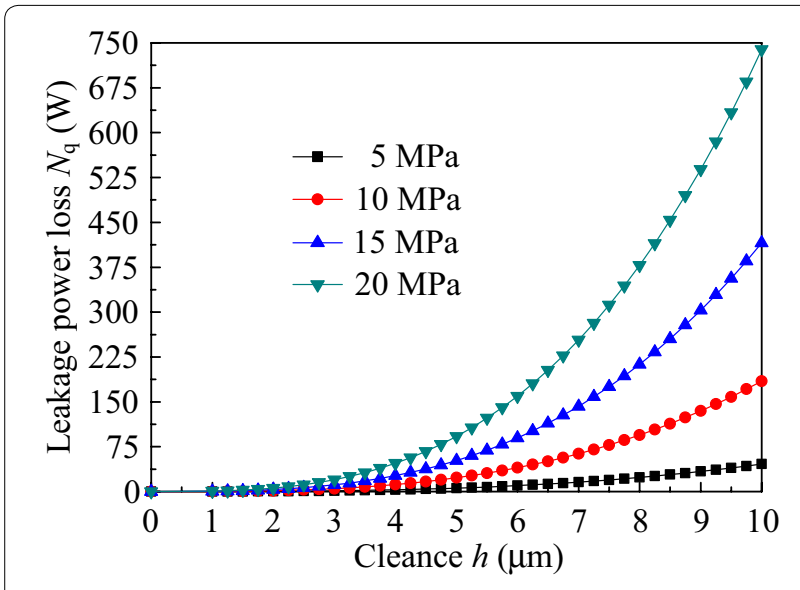

Figure 5 Change of leakage power loss with clearance

leakage power loss at various pressures are analyzed, as shown in Figures 4 and 5.

As shown in Figure 4, the friction power loss reduces with the increase of clearance and rises with the increase of rotating speed. Consequently, the rotating speed should not be too high and the clearance of port plate pairs should not be too small, otherwise it will cause greater friction power loss. From Figure 5, it can be seen that the leakage power loss will increase with the increase of clearance and pressure. When the pressure is greater than $10 \mathrm{MPa}$, the curve slope of the leakage power loss rises sharply with the increase of clearance, which finally results in more serious leakage power loss. Therefore, the clearance of port plate pairs should not be too large and the pressure should not be too high.

When the pressure of water hydraulic is $10 \mathrm{MPa}$, the total power loss can be got by Eq. (9). And the relations of clearance with total power loss at different rotating

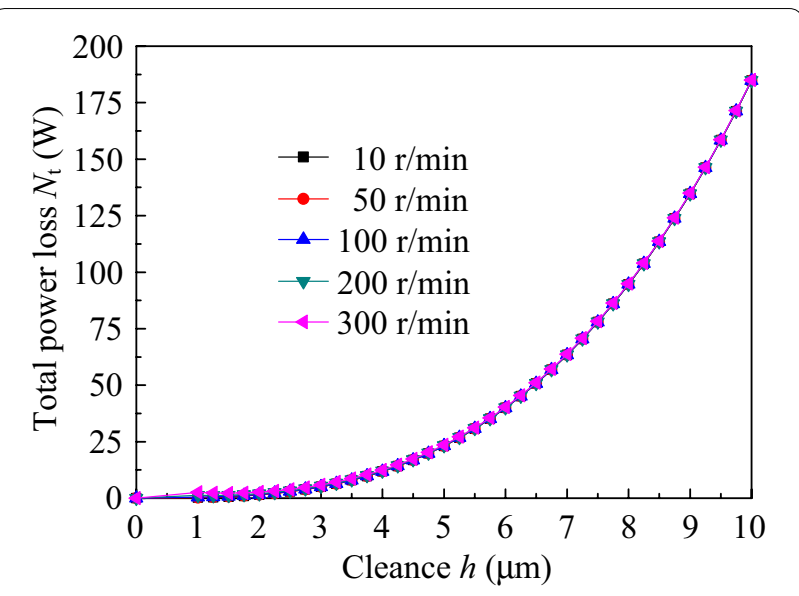

Figure 6 Change of total power loss with clearance at various rotating speed

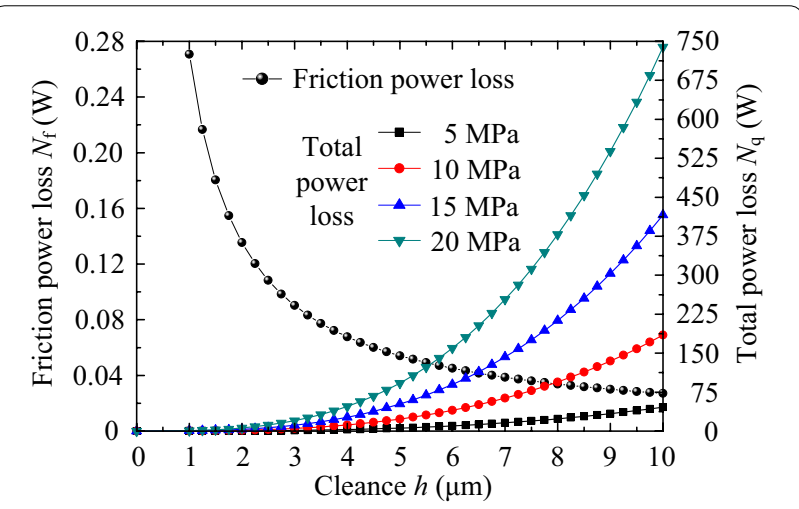

Figure 7 Change of friction and total power loss with clearance

speeds are shown in Figure 6. When the rotating speed is $100 \mathrm{r} / \mathrm{min}$, the total power loss can be also got by Eq. (9). And the relations of clearance with total power loss at different pressures are shown in Figure 7.

Figures 6 and 7 show that both the total power loss under different rotating speeds and pressures increase with the increase of clearance. When the clearance is greater than $5 \mu \mathrm{m}$, the rate of increase becomes larger. Figure 6 also indicates that the total power under different rotating speeds is almost a constant. Figures 5 and 7 show that the increase of the total power loss is associated with the leakage power loss. Therefore, the friction power loss is negligible compared with the leakage power loss.

Based on the parameters related to the equation and neglecting the pressure drop, the optimum clearance of port plate pairs is got by Eq. (10). And the optimal clearance-rotating speed curve of distribution pair is shown in Figure 8. 


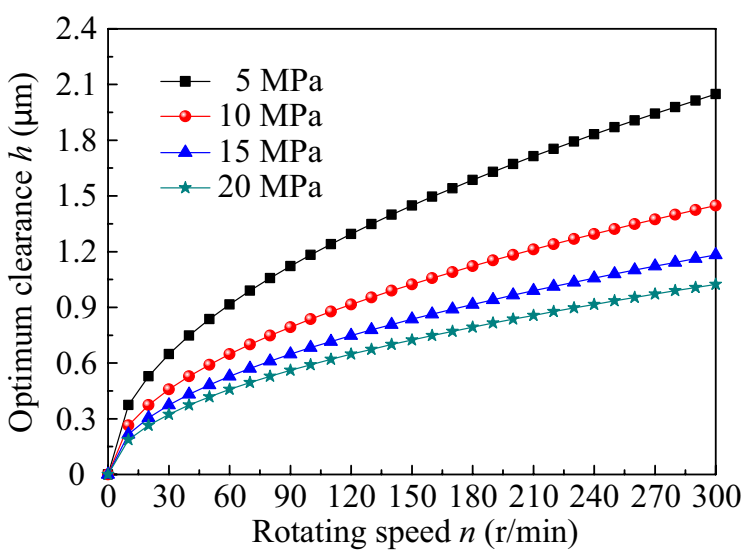

Figure 8 Change of optimal clearance with rotating speed at various pressures

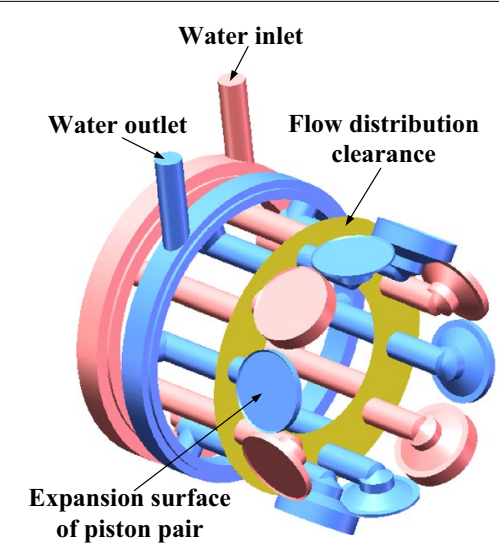

Figure 9 Internal flow channel of seawater hydraulic motor

Figure 8 demonstrates the optimal clearance of port plate pairs increases with the increase of the rotating speed, and decreases with the increase of the pressure. The results show that the optimal clearance of port plate pairs is proportional to the output rotational speed, and inverse proportional to the pressure.

\section{Numerical Simulation of Flow Field of Port Plate Pairs}

A geometry model of the flow channel in the port plate is established by using 3D software. Figure 9 shows the whole flow channel model of port plate pairs. The model is comprised of water inlet chamber, water outlet chamber, internal flow channel of port plate, water film of port plate and rotor, internal flow channel of rotor and flow channel of piston pairs.

\subsection{Boundary Conditions of Model}

The pressure boundary conditions are imposed on the inlet and the outlet. And the boundary conditions of mode are given according to the practical operation in seawater hydraulic motor. The rated pressure of the motor is $10 \mathrm{MPa}$, so the pressure of inlet is set to $10 \mathrm{MPa}$. Meanwhile, due to the leakage of clearance of port plate pairs and piston pairs, the pressure boundary conditions are also imposed on the side of water film and the pressure of outlet is $0.5 \mathrm{MPa}$.

\subsection{Simulation Results and Analysis \\ 4.2.1 Effect of Water Film on Pressure and Velocity Distribution}

Figure 10 shows the pressure and velocity distribution of port plate pairs at different water film. As shown in Figure 10a, the velocity distribution of water film section presents obviously flow rotation characteristics. There is also a cross regional "speed wing" circulating counterclockwise at all the low and high pressure area. It's a phenomenon of encapsulation and interaction between the high pressure area and low pressure area. Meanwhile, two negative pressure points have appeared in low pressure area. This is because the negative pressure points are located off the switching area of water inlet and outlet of port plate. Excessively high speed, pressure difference and small flow area cause trouble to exchange liquid effectively in the clearance of port plate and rotor, and then will lead to negative pressure which is easy to cause cavitation. It can cause many problems, such as the surface damage of port plate pairs, noise and vibration. Thus, the flow distribution water film should not too thin.

In Figure 10b, cross-linking of velocity has appeared in contiguous areas of high pressure. According to the no slip theory, the water film next to the rotor will have the same velocity as the rotor. However, when the film is quite thick, the influence of this factor on the velocity distribution of water film is not obvious. As the water film decrease, the effect of the rotor rotating on the velocity distribution of water film will be more and more obvious.

Figure 10c and d show that the pressure distribution of water film under $8 \mu \mathrm{m}$ and $10 \mu \mathrm{m}$ are coincident. From Figure $10 \mathrm{a}-\mathrm{d}$, it can be seen that the maximum pressure amplitude of water film decrease and the velocity increase greatly with the increase of water film. However, the flow rotation characteristics will no longer be visible.

\subsubsection{Effect of Water Film on Leakage Flow}

Figure 11 illustrates that the change of leakage flow of port plate pairs with water film thicknesses at different time. As can be seen, the leakage flow increase with the increase of water film. When the water film thicknesses is 


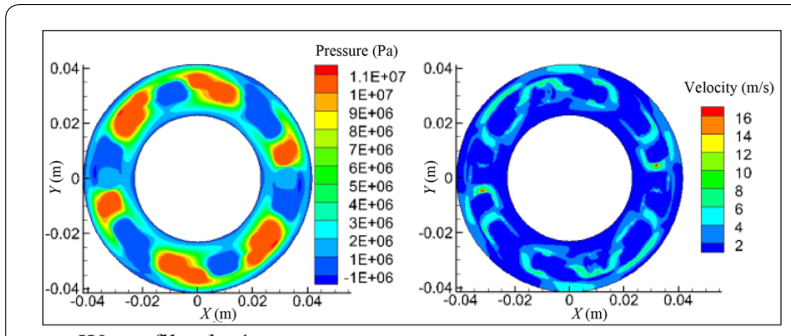

a Water film $h=4 \mu \mathrm{m}$

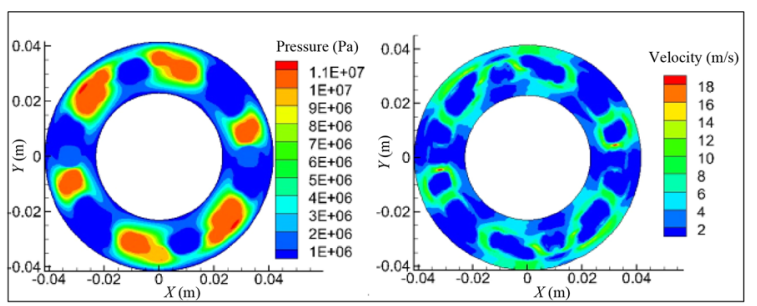

b Water film $h=6 \mu \mathrm{m}$

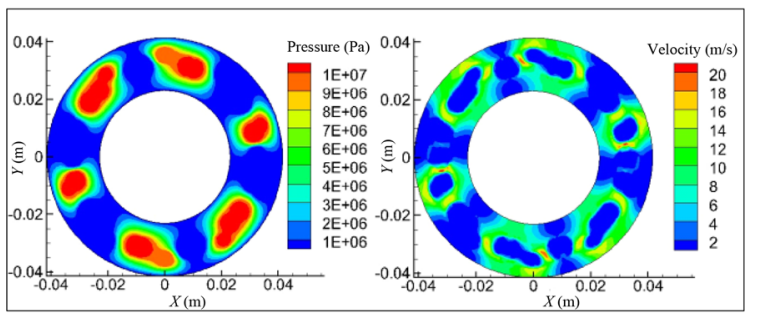

c Water film $h=8 \mu \mathrm{m}$

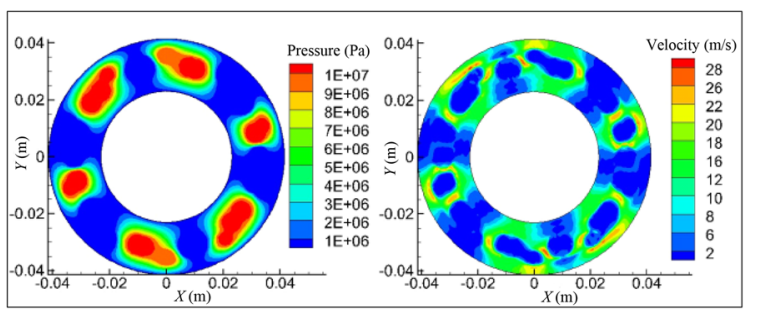

d Water film $h=10 \mu \mathrm{m}$

Figure 10 Pressure and velocity contour of flow distribution water film

$4 \mu \mathrm{m}$, the port plate pairs exhibit the lowest average leakage flow of $0.06 \mathrm{~L} / \mathrm{min}$, while it shows the highest average leakage flow as $0.80 \mathrm{~L} / \mathrm{min}$ under $10 \mu \mathrm{m}$. So the larger clearance, the higher leakage flow. By comparing Figure 3 , it can be seen that the variations of CFD simulation and theoretical calculation are in accordance.

Through the analysis of the effect of water film thicknesses on pressure distribution, velocity distribution and the leakage flow, it can be denoted that when the water film is $10 \mu \mathrm{m}$, the leakage flow will very large and the volumetric efficiency will very low. It doesn't conform to practical applications. When the water film are $4 \mu \mathrm{m}$ and $6 \mu \mathrm{m}$, the pressure and velocity distribution

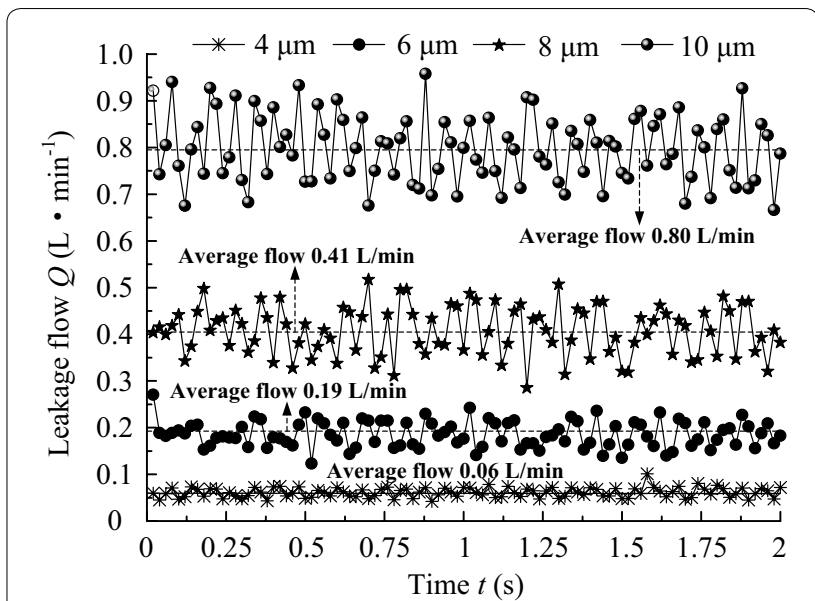

Figure 11 Leakage flow of port plate pairs at various water film thicknesses

are obviously unsatisfactory, and even appear to negative pressure which will cause the cavitation damage of port plate pairs. When the water film is $8 \mu \mathrm{m}$, the pressure distribution and velocity distribution are more balanced. Consequently, taking the pressure distribution, velocity distribution, leakage flow and manufacture into consideration, the water film thickness should be controlled at about $6-8 \mu \mathrm{m}$.

\subsubsection{Effect of Inlet Pressure Distribution}

The inlet pressure of motor as a principal parameter is taking an important role in the inside flow characteristics of motor. In order to analyze the influence of inlet pressure on the performance of port plate pairs, the water film of port plate and rotor is set to $8 \mu \mathrm{m}$, the rotating speed is set to $30 \mathrm{r} / \mathrm{min}$, and the inlet pressure is set to $5 \mathrm{MPa}, 10 \mathrm{MPa}, 15 \mathrm{MPa}$ and $20 \mathrm{MPa}$, respectively. Figure 12 demonstrates the pressure contour of port plate pairs at the four different inlet pressures.

By comparing these pressure contour pictures, it can be seen that the pressure distribution has slightly different when the inlet pressure is $5 \mathrm{MPa}$ and the other three pressures (10 MPa, $15 \mathrm{MPa}$ and $20 \mathrm{MPa})$. When the inlet pressure is $5 \mathrm{MPa}$, the pressure distribution is similar to a radial distribution. And the distribution of other three pressures trend to circumferential distribution. Overall, there is not much difference between the four distributions. Thus, the inlet pressure of seawater hydraulic motor has no significant effect on the pressure distribution of port plate pairs.

\subsubsection{Effect of Inlet Pressure on Leakage Flow}

Figure 13 shows the change of leakage flow of port plate pairs with inlet pressure at different time. As shown in 


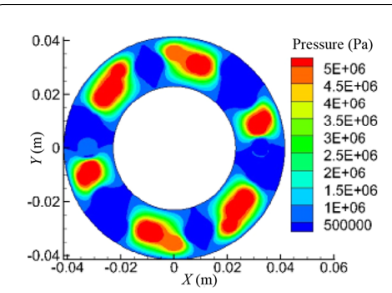

a Inlet pressure $p_{\mathrm{s}}=5 \mathrm{MPa}$

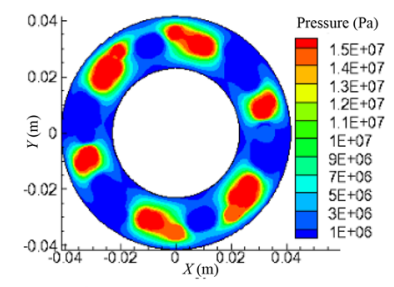

c Inlet pressure $p_{\mathrm{s}}=15 \mathrm{MPa}$

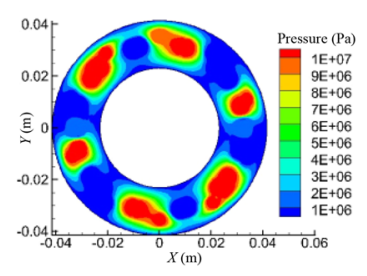

b Inlet pressure $p_{\mathrm{s}}=10 \mathrm{MPa}$

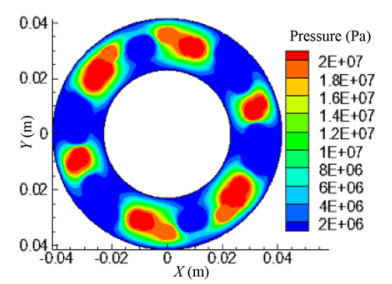

d Inlet pressure $p_{\mathrm{s}}=20 \mathrm{MPa}$
Figure 12 Pressure distribution of port plate pairs at various inlet pressures

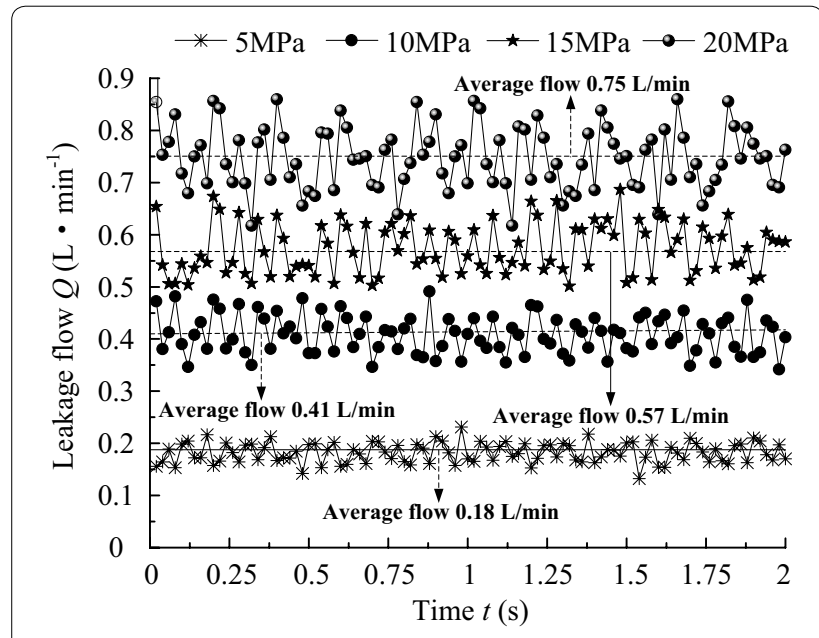

Figure 13 Leakage flow of port plate pairs at various inlet pressure

the figure, the leakage flow of CFD simulation also rises with increased inlet pressure. When the inlet pressure is $5 \mathrm{MPa}$, the port plate pairs exhibit the lowest average leakage flow as $0.18 \mathrm{~L} / \mathrm{min}$, whereas it shows the highest average leakage flow of $0.75 \mathrm{~L} / \mathrm{min}$ under the $20 \mathrm{MPa}$. The CFD simulation trend of leakage flow is coincided with theoretical calculation, as shown in Figure 3. Viewed from the numerical results, the leakage flow changes linearly with increasing inlet pressure. So the inlet pressure of seawater hydraulic motor should not too high.

\subsubsection{Effect of Rotating Speed on Leakage Flow}

Due to little variation of different rotating speeds on pressure distribution, the pressure contour of flow distribution is not given. And the leakage flow of different rotating speeds is analyzed. Figure 14 demonstrates the change of leakage flow of port plate pairs with increasing test time at different rotating speeds. The simulation results show the effect of different rotating speeds on the leakage flow is not very obvious. This is consistent with the leakage flow calculated by formula in which the rotating speed is omitted. It could be also validated by the change of total power loss with clearance at various rotating speed, as shown in Figure 6. The effect of rotating speed mostly reflects on the rang of fluctuation. When the rotating speed is low, the leakage flow curve fluctuates greatly. And when the rotational speed increases, the fluctuation of leakage flow decrease. As shown in Figure 14, the leakage flow of port plate pairs fluctuates around 0.35-0.42 under the rotational speed of $240 \mathrm{r} / \mathrm{min}$.

\section{Friction and Wear of Port Plate Pairs}

The experiments are performed with a rotational speed of $100 \mathrm{r} / \mathrm{min}$ and period of $2 \mathrm{~h}$. And the port plate and rotor are fabricated from stainless steel 316L and CFRPEEK, respectively. The properties of 316L and CFRPEEK are presented in Tables 2 and 3.

Figure 15 shows the variation of the friction coefficient and temperature of port plate pairs with increasing test time. As illustrated in the figure, the friction coefficient of port plate pairs is around 0.1 until the end of the test time. It doesn't have a running-in period. The value of temperature increases dramatically from $0 \mathrm{~s}$ to $2400 \mathrm{~s}$. And it has some fluctuations within $2400-6400 \mathrm{~s}$. After $6400 \mathrm{~s}$, the temperature stabilizes at $32.8^{\circ} \mathrm{C}$.

To further investigate the specific changes in the surface of port plate pairs, the wear scars and height variations of wear scars are observed by a laser scanning

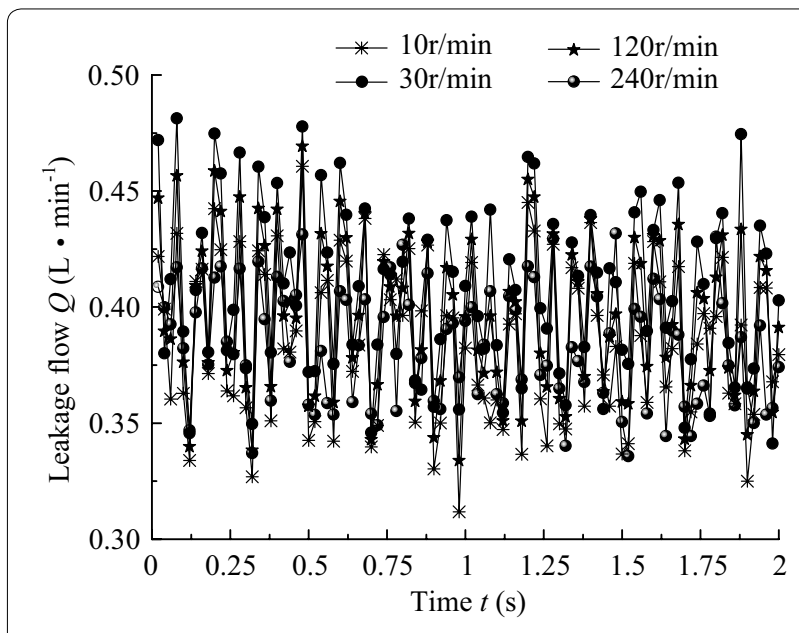

Figure 14 Leakage flow of port plate pairs at various rotating speed 
Table 2 Main performance parameters of $316 \mathrm{~L}$

\begin{tabular}{|c|c|c|c|c|c|c|}
\hline Density $\left(\mathrm{g} / \mathrm{cm}^{3}\right)$ & $\begin{array}{l}\text { Modulus of elasticity } \\
\text { (GPa) }\end{array}$ & Brinell hardness & Elongation (\%) & $\begin{array}{l}\text { Coefficient } \\
\text { of thermal } \\
\text { expansion }\left(10^{-6} /{ }^{\circ} \mathrm{C}\right)\end{array}$ & $\begin{array}{l}\text { Tensile strength } \\
\text { (MPa) }\end{array}$ & Yield strength (MPa) \\
\hline 8.03 & 206 & 230 & 30 & 16 & 620 & 310 \\
\hline
\end{tabular}

Table 3 Properties of CFRPEEK

\begin{tabular}{|c|c|c|c|c|c|c|}
\hline Density $\left(\mathrm{g} / \mathrm{cm}^{3}\right)$ & $\begin{array}{l}\text { Water absorption } \\
\text { after } 24 \mathrm{~h} \\
\text { immersion in water } \\
\text { of } 23^{\circ} \mathrm{C}(\%)\end{array}$ & Rockwell hardness & $\begin{array}{l}\text { Coefficient } \\
\text { of thermal } \\
\text { expansion } \\
\left(10^{-5} /{ }^{\circ} \mathrm{C}\right)\end{array}$ & $\begin{array}{l}\text { Tensile strength } \\
\text { at } 23^{\circ} \mathrm{C}(\mathrm{MPa})\end{array}$ & $\begin{array}{l}\text { Bending strength } \\
\text { at } 23^{\circ} \mathrm{C}(\mathrm{MPa})\end{array}$ & $\begin{array}{l}\text { Compressive } \\
\text { strength (MPa) }\end{array}$ \\
\hline 1.4 & 0.06 & 107 & 1.5 & 220 & 298 & 240 \\
\hline
\end{tabular}

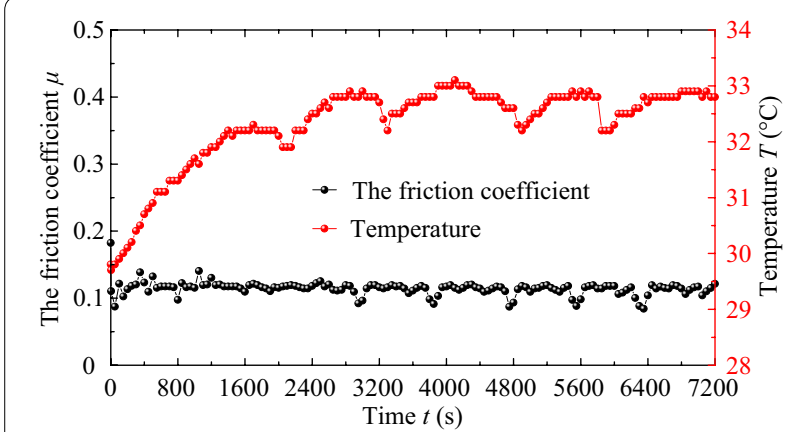

Figure 15 Variation of the friction coefficient and temperature of port plate pairs with test time

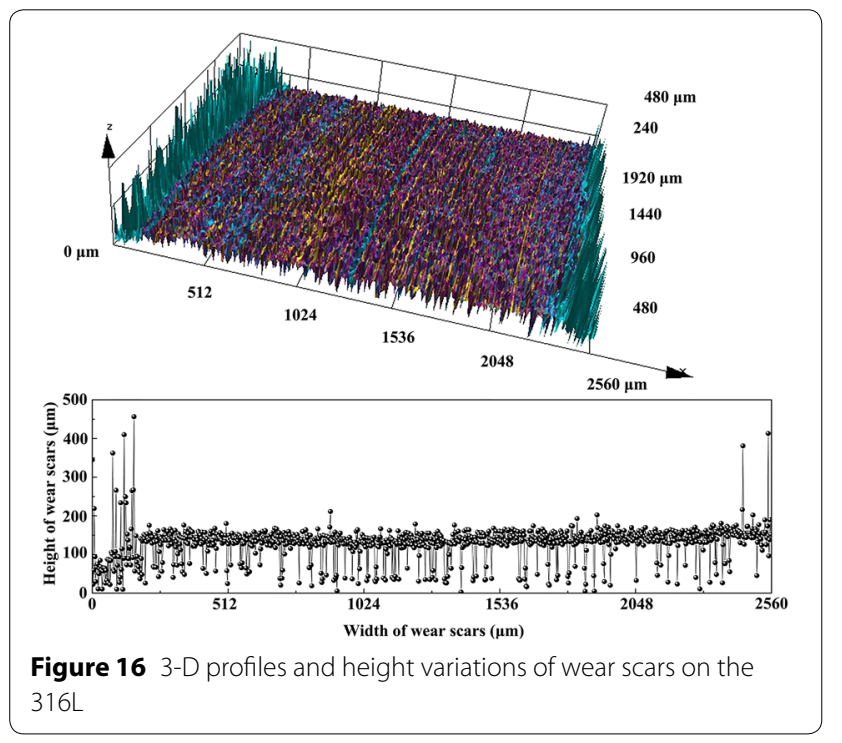

confocal microscope, as shown in Figures 16 and 17. In Figure 16, the surface of 316L exhibits a lot of small scratches and some "needles" know as the no contact

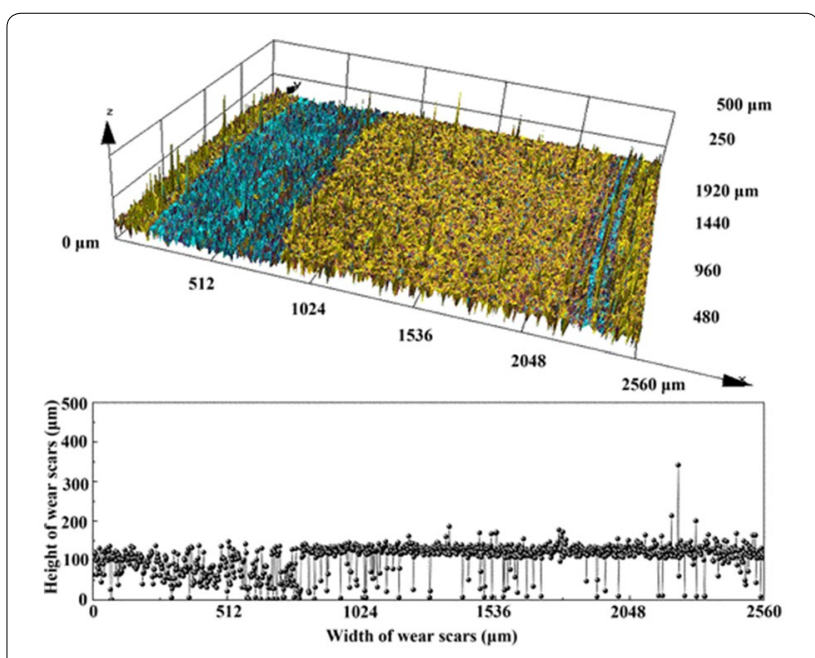

Figure 17 3-D profiles and height variations of wear scars on the CFRPEEK

surface areas. This is consistent with the height variations of wear scars, as shown in the figure. Numerous trenches are ploughed on the contact surface, and the mean depth of the trenches is about $130 \mu \mathrm{m}$ with width ranging from $150 \mu \mathrm{m}$ to $2400 \mu \mathrm{m}$. Moreover, the surface of 316L has a mean surface roughness $R_{\mathrm{a}}$ of approximately $30.9 \mu \mathrm{m}$. The worn surface of CFRPEEK is smooth without extensive scratches or grooves. It exhibits only a little linear or lamellate wear at its edges, as shown in Figure 17. The observation agrees well with the result of height variations. Although the grooves have widths ranging from $100 \mu \mathrm{m}$ to 800 $\mu \mathrm{m}$, their mean depth is low, which is around 120 $\mu \mathrm{m}$. In addition, the worn surface of CFRPEEK has a mean roughness $R_{\mathrm{a}}$ of approximately $22.6 \mu \mathrm{m}$. The results indicate that the friction pairs of $316 \mathrm{~L}$ against CFRPEEK have reasonable wear resistance, small 


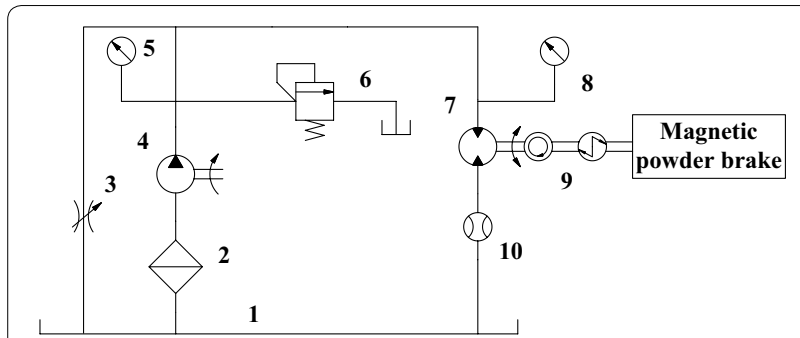

Figure 18 Principle diagram of experimental system of seawater hydraulic motor. 1. Water tank; 2 . Filter; 3 . Water hydraulic throttling valve; 4 . Water hydraulic pump; 5 , 8. Pressure gauge; 6 . Water relief valve; 7 . Water hydraulic motor; 9 . Intelligent digital tacho-torquemeter; 10. Flowmeter

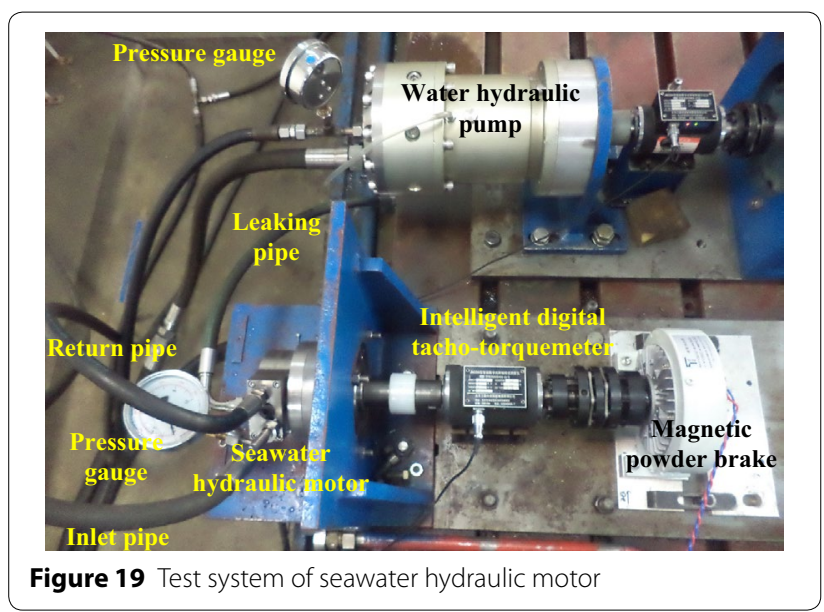

seawater temperature change and a lower friction coefficient. Therefore, the counter materials of $316 \mathrm{~L}$ and CFRPEEK are suitable for the port plate pairs of seawater hydraulic motor.

\section{Experimental Results of Seawater Hydraulic Motor}

In order to verify the rationality of structure design and the material selection of port plate pairs of seawater hydraulic motor, the experiment platform is built. And the no-load and loading test of seawater hydraulic are respectively carried out to analyze the characteristics of prototype. Figures 18 and 19 present the principle diagram and the test system of seawater hydraulic motor.

The experimental results under no-load and loading are presented in Tables 4, 5, 6. The test data shows that with the increase of input flow of seawater hydraulic motor, the output flow becomes larger, and the rotating speed also increases. At the same rotating speed, enhancing the load torque will make the internal pressure of seawater hydraulic motor rise and the volumetric efficiency reduce. On the contrary, the volumetric efficiency is proportional to the rotating speed at the same load condition. Taking no-load seawater hydraulic motor as example, the volumetric efficiency is $84.49 \%$ when the rotating speed is $55 \mathrm{r} / \mathrm{min}$. If the rotating speed reaches to $200 \mathrm{r} / \mathrm{min}$, then the volumetric efficiency will achieve $94.71 \%$.

To further investigate the structure and the model rationality of port plate pairs, the error rate changes under different load conditions are analyzed, as shown in Figure 20. As shown in the figure, the error rates of three different conditions are obviously high in low speed area. However, the error rate gradually decreases and tends to be stable with the increase of the rotating speed. That's because in the low speed,

Table 4 Flow rate results of seawater hydraulic motor under no-load state

\begin{tabular}{|c|c|c|c|c|c|c|}
\hline Pressure (MPa) & $\begin{array}{l}\text { Rotating speed } \\
\text { (r/min) }\end{array}$ & Input flow (L/min) & $\begin{array}{l}\text { Output flow (L/ } \\
\text { min) }\end{array}$ & $\begin{array}{l}\text { Calculated flow } \\
\text { (L/min) }\end{array}$ & Error rate (\%) & $\begin{array}{l}\text { Volumetric } \\
\text { efficiency (\%) }\end{array}$ \\
\hline 0.7 & 55 & 7.624 & 6.442 & 6.040 & 6.24 & 84.49 \\
\hline 0.7 & 62 & 8.704 & 7.440 & 6.895 & 7.33 & 86.62 \\
\hline 0.7 & 74 & 9.820 & 8.628 & 8.361 & 3.09 & 87.86 \\
\hline 0.7 & 84 & 11.018 & 9.784 & 9.582 & 2.06 & 88.80 \\
\hline 0.7 & 95 & 12.246 & 10.900 & 10.925 & 0.23 & 89.01 \\
\hline 0.7 & 108 & 14.220 & 12.908 & 12.513 & 3.06 & 90.77 \\
\hline 0.7 & 128 & 16.868 & 15.402 & 14.956 & 2.90 & 91.31 \\
\hline 0.7 & 145 & 18.354 & 16.980 & 17.033 & 0.31 & 92.51 \\
\hline 0.7 & 156 & 19.754 & 18.436 & 18.376 & 0.33 & 93.33 \\
\hline 0.7 & 164 & 20.656 & 19.306 & 19.353 & 0.24 & 93.46 \\
\hline 0.7 & 173 & 21.592 & 20.330 & 20.453 & 0.61 & 94.16 \\
\hline 0.7 & 184 & 23.570 & 22.208 & 21.796 & 1.86 & 94.22 \\
\hline 0.7 & 200 & 25.498 & 24.148 & 23.751 & 1.64 & 94.71 \\
\hline
\end{tabular}


Table 5 Flow rate results of seawater hydraulic motor under load condition 1

\begin{tabular}{llllllll}
\hline Pressure (MPa) & $\begin{array}{l}\text { Rotating } \\
\text { speed (r/min) }\end{array}$ & Input flow (L/min) & $\begin{array}{l}\text { Output flow } \\
\text { (L/min) }\end{array}$ & $\begin{array}{l}\text { Calculated } \\
\text { flow (L/min) }\end{array}$ & Error rate (\%) & $\begin{array}{l}\text { Output } \\
\text { torque (N m) }\end{array}$ & $\begin{array}{l}\text { Volumetric } \\
\text { efficiency (\%) }\end{array}$ \\
\hline 1.5 & 55 & 7.635 & 6.015 & 5.215 & 13.30 & 27 & 78.78 \\
1.6 & 64 & 8.728 & 6.979 & 6.022 & 13.71 & 28 & 79.96 \\
1.6 & 75 & 10.083 & 8.163 & 7.269 & 10.95 & 28 & 80.96 \\
1.6 & 84 & 11.382 & 9.317 & 8.710 & 6.51 & 29 & 81.86 \\
1.6 & 93 & 12.446 & 10.253 & 9.808 & 4.34 & 28 & 82.38 \\
1.7 & 131 & 13.183 & 11.008 & 10.689 & 2.90 & 29 & 83.50 \\
1.7 & 113 & 14.556 & 12.272 & 12.154 & 0.96 & 28 & 84.31 \\
1.6 & 125 & 16.086 & 13.696 & 13.717 & 0.15 & 28 & 85.14 \\
1.6 & 142 & 18.169 & 15.803 & 15.794 & 0.06 & 28 & 86.98 \\
1.6 & 154 & 19.373 & 16.946 & 17.259 & 1.85 & 29 & 87.47 \\
1.7 & 166 & 20.909 & 18.458 & 18.628 & 0.92 & 29 & 88.28 \\
1.6 & 183 & 23.252 & 20.788 & 20.802 & 0.07 & 29 & 89.40 \\
\hline
\end{tabular}

Table 6 Flow rate results of seawater hydraulic motor under load condition 2

\begin{tabular}{|c|c|c|c|c|c|c|c|}
\hline Pressure (MPa) & $\begin{array}{l}\text { Rotating } \\
\text { speed (r/min) }\end{array}$ & Input flow (L/min) & $\begin{array}{l}\text { Output flow } \\
\text { (L/min) }\end{array}$ & $\begin{array}{l}\text { Calculated } \\
\text { flow (L/min) }\end{array}$ & Error rate (\%) & $\begin{array}{l}\text { Output } \\
\text { torque ( } \mathrm{N} \mathrm{m})\end{array}$ & $\begin{array}{l}\text { Volumetric } \\
\text { efficiency (\%) }\end{array}$ \\
\hline 2.7 & 58 & 7.520 & 5.122 & 4.467 & 12.79 & 40 & 68.11 \\
\hline 3.0 & 71 & 8.967 & 6.434 & 5.764 & 10.41 & 40 & 71.75 \\
\hline 3.0 & 82 & 10.325 & 7.497 & 7.108 & 5.19 & 41 & 72.61 \\
\hline 3.2 & 93 & 11.556 & 8.438 & 8.257 & 2.15 & 41 & 73.02 \\
\hline 3.2 & 110 & 14.471 & 10.777 & 10.334 & 4.11 & 40 & 74.48 \\
\hline 3.2 & 121 & 15.947 & 12.002 & 11.678 & 2.70 & 40 & 75.27 \\
\hline 3.4 & 138 & 17.835 & 13.870 & 13.560 & 2.24 & 40 & 77.77 \\
\hline 3.6 & 152 & 19.339 & 15.317 & 15.076 & 1.57 & 40 & 79.21 \\
\hline 3.6 & 163 & 20.227 & 16.334 & 16.053 & 1.72 & 40 & 80.75 \\
\hline 3.4 & 175 & 21.959 & 17.972 & 18.079 & 0.60 & 41 & 81.84 \\
\hline 3.4 & 184 & 23.052 & 19.043 & 19.179 & 0.70 & 40 & 82.61 \\
\hline 3.4 & 200 & 25.389 & 21.446 & 21.133 & 1.46 & 40 & 84.47 \\
\hline
\end{tabular}

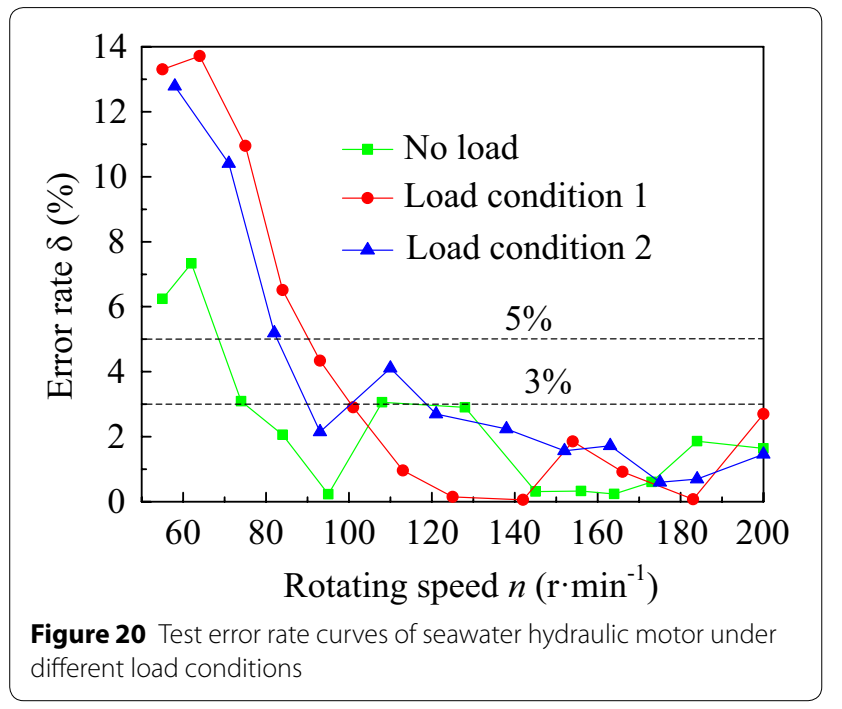

the input flow of seawater hydraulic is small and the laminar flow condition of port plate pairs is not sufficient in the low speed. Whereas the theoretical model is to omit the correction factor of laminar flow primary section, which finally results in a larger leakage flow. When the rotating speed exceeds $70 \mathrm{r} / \mathrm{min}$, it is regarded that the laminar flow condition is sufficient. And the correction factor of laminar flow is around 1, so it can be ignored. The error in calculation is within $5 \%$. When the rotating speed exceeds $100 \mathrm{r} / \mathrm{min}$, the error rate has been controlled in about 3\%. At this point, the superiority of leakage flow model of port plate pairs has been fully demonstrated and the model can accurately reflect the flow characteristic of seawater hydraulic motor. As a result, the correctness of the model not only has been verified directly, but also 
lays a good base for further development of seawater hydraulic motor in the future.

\section{Conclusions}

Based on the analysis of numerical and experimental results, the performance of port plate pairs of low speed high torque seawater hydraulic motor, the following conclusions can be drawn.

1. Compared with the leakage power loss, the friction power loss is negligible. The leakage flow and total power loss increase with the increase of clearance and pressure, but the total power of different rotating speeds is almost a constant. Meanwhile, the optimal clearance of port plate pairs is proportional to the output rotational speed, and inverse proportional to the pressure.

2. Numerical simulation shows that the leakage flow of CFD simulation also rises with the increase of inlet pressure and clearance. And the effect of different rotating speeds on the leakage flow is not very obvious. These results are coincided with theoretical calculation. Consequently, taking the pressure distribution, velocity distribution, leakage flow and manufacture into consideration, the clearance should be controlled at about $6-8 \mu \mathrm{m}$.

3. The friction and wear results indicate that the port plate pairs of 316L against CFRPEEK have reasonable wear resistance, small seawater temperature change and a lower friction coefficient. Therefore, the counter materials of 316L and CFRPEEK are suitable for the port plate pairs of seawater hydraulic motor.

4. The experimental results show that the model can accurately reflect the flow characteristic of seawater hydraulic motor when the rotating speed of seawater hydraulic motor exceeds $70 \mathrm{r} / \mathrm{min}$. When the rotating speed exceeds $100 \mathrm{r} / \mathrm{min}$, the error rate has been controlled in about 3\%. However, when the rotating speed is $0-70 \mathrm{r} / \mathrm{min}$, the correction factor of the model needs to be determined by combining the specific structure parameters. Moreover, the principle prototype of seawater hydraulic motor has smooth operation and high efficiency in the no-load and loading tests. Their maximum volumetric efficiencies can achieve $94.71 \%$ and $90.14 \%$, respectively. It also verified the correctness of the study results.

\section{Authors' Contributions}

ZW and DG were in charge of the whole trial; ZW wrote the manuscript; S-FW and S-CW assisted with sampling and laboratory analyses. All authors read and approved the final manuscript.

\section{Authors' Information}

Zhiqiang Wang, born in 1984, is currently an Associate Professor at Hangzhou Dianzi University, China. He received his PhD degree from Yanshan University, China, in 2014. His research interests include lubrication mechanism, friction and wear of seawater hydraulic motor.

Shaofeng Wu, born in 1987, is currently a Lecture at Hangzhou Dianzi University, China. He received his PhD degree from Yanshan University, China, in 2016.

Dianrong Gao, born in 1962, is currently a Professor at Yanshan University, China. He received his PhD degree from Yanshan University, China, in 2001. Shuncai Wang, born in 1964, is currently a Lecturer within Engineering and Physical Sciences at the University of Southampton, UK. He received his PhD degree from University of Birmingham, UK, in 1998.

\section{Acknowledgements}

The authors sincerely thanks to Professor Dianrong Gao of Yanshan University for his critical discussion and reading during manuscript preparation.

\section{Competing Interests}

The authors declare that they have no competing interests.

\section{Funding}

Supported by National Natural Science Foundation of China (Grant Nos. 51505111, 51805125), Zhejiang Provincial National Natural Science Foundation of China (Grant No. LQ16E050003), Hebei Provincial National Natural Science Foundation of China (Grant No. E2015203006), and Open Foundation of State Key Laboratory of Fluid Power and Mechatronic Systems (Grant No. GZKF-201519).

\section{Author Details \\ ${ }^{1}$ School of Mechanical Engineering, Hangzhou Dianzi University, Hang- zhou 310018, China. ${ }^{2}$ Zhejiang University, Hangzhou 310058, China. ${ }^{3}$ cnCATS, Faculty of Engineering and the Environment, University of Southampton, Southampton, UK. ${ }^{4}$ School of Mechanical Engineering, Yanshan University, Qinhuangdao 066004, China.}

Received: 2 May 2019 Revised: 26 October 2019 Accepted: 5 December 2019

Published online: 18 December 2019

\section{References}

[1] E Strmčnik, F Majdič, M Kalin. Water-lubricated behaviour of AISI $440 C$ stainless steel and a DLC coating for an orbital hydraulic motor application. Tribology International, 2019, 131: 128-136.

[2] P Traverso, E Canepa. A review of studies on corrosion of metals and alloys in deep-sea environment. Ocean Engineering, 2014, 87:10-15.

[3] H J Kim, D E Kim. Water lubrication of stainless steel using reduced graphene oxide coating. Scientific Reports, 2015, 5: 1-13.

[4] Y S Liu, Y P Deng, M S Fang, et al. Research on the torque characteristics of a seawater hydraulic axial piston motor in deep-sea environment. Ocean Engineering, 2017, 146: 411-423.

[5] X D Lu, J Zhao, J L Mo, et al. Improvement of dynamical and tribological properties of friction systems by introducing parallel-grooved structures in elastic damping components. Composite Structures, 2018, 192: 8-19.

[6] EStrmcnik, F Majdič. Comparison of leakage level in water and oil hydraulics. Advances in Mechanical Engineering, 2017, 9:1-12.

[7] A Takeuchi. Ultrasonic measurement of film thickness in partial water repellent full-Flat thrust bearing. Transactions of the Japan Society of Mechanical Engineers, 2013, 79: 2164-2173.

[8] S A Black. Development and evaluation of an experimental seawater hydraulic tool system for U.S. navy divers. Offshore Technology Conference, Houston, USA, 1984: 135-139.

[9] J P Kunsemiller. Development of a seawater hydraulic rock drill. http:// www.dtic.mil/docs/citations/ADA235873 (1991).

[10] J P Kunsemiller, S A Black. Seawater hydraulics: a multi-function tool system for U.S. navy construction divers. http://www.dtic.mil/docs/citat ions/ADA237947 (1991). 
[11] J A Currie. The development of raw water hydraulics. Proc. of 1st Bath Int. Fluid Power Workshop, University of Bath, UK, 1988: 126-130.

[12] E Trostmann. Water hydraulics control technology. New York: Marcel Dekker. Inc., 1996

[13] F Conrad, A Adelstorp. Tap water hydraulic control systems for medium power application areas. 10th Bath International Fluid Power Workshop, University of Bath, England, UK, 1997: 117-130.

[14] L S Drabløs. Testing of danfoss APP10-22 with APP pumps as water hydraulic motors for energy recovery. Desalinisation, 2005, 183: 41-54

[15] C H Lim, P S Chua, Y B He. The modern water hydraulics-the new energy-transmission technology in fluid power. Applied Energy, 2003, 76: 239-246.

[16] C Finn, P Janus, S Andrzej. It-tools concept for simulation and design of water hydraulic mechatronic test facilities for motion control and operation in environmentally sensitive application areas. 2004 ASME International Mechanical Engineering Congress and Exposition, IMECE, Anaheim, USA, 2004: 277-285.

[17] DC Hicks, C M Pleass. Development and testing of a composite/plastic high pressure seawater pump. Engineering Optimization, 1986, 3: 69-78.

[18] H Yoshinada, TYamazaki, T Suwa. Seawater hydraulic actuator system for underwater manipulator. Hydraulics \& Pneumatics, 1991, 22: 48-55.

[19] M Shinoda, C Yamashina, S Miyakawa. Development of low-pressure water hydraulic motor. The Sixth Scandinavian International Conference on Fluid Power, Tampere, Finland, 1999: 243-254

[20] S Oshima, T Hiranao. Investigation for output torque of a low pressure water hydraulic planetary gear motor. Vodna Hidravlika, 2012, 18: 26-35.

[21] H Wang, Z Liu, L Zou, J Yang. Influence of both friction and wear on the vibration of marine water lubricated rubber bearing. Wear, 2017, 376: 920-930.

[22] X Liang, X Yan, Z Liu, et al. Design and performance analysis of a water lubricated tilting pad thrust bearing. Journal of Traffic and Transportation Engineering, 2017, 17: 89-97.

[23] X Liang, X Yan, OY Wu, et al. Thermo-Elasto-Hydrodynamic analysis and optimization of rubber-supported water-lubricated thrust bearings with polymer coated pads. Tribology International, 2019, 138: 365-379.

[24] P N Pham, K Ito, S Ikeo. The application of simple adaptive control for simulated water hydraulic servo motor system. IEEE International Conference on Industrial Technology, Cape Town, SouthAfrica, 2013: 204-209.

[25] P N Pham, K Ito. Energy-saving technology for water hydraulic motor system (First report: simulation result). Journal of Advanced Mechanical Design Systems \& Manufacturing, 2016, 10: 1-13.
[26] L Aha, JVäyrynen, J Tammisto, et al. Servo valve endurance test for waterhydraulic systems in ITER-relevant conditions. Fusion Engineering and Design, 2019, 146: 2523-2526.

[27] J Väyrynen, L Aha, J Mattila, et al. Heat management for water-hydraulic systems at ITER remote handling. Fusion Engineering and Design, 2019, 146: 2314-2318.

[28] Y Kim, J H Lee, Y C Kim, et al. Operation and simulation of pilot-scale forward osmosis desalination with ammonium bicarbonate. Chemical Engineering Research and Design, 2015, 94: 390-395.

[29] F L Yin, S L Nie, W Hou, et al. Effect analysis of silencing grooves on pressure and vibration characteristics of seawater axial piston pump. Journal of Mechanical Engineering Science, 2017, 231: 1390-1409.

[30] F L Yin, S L Nie, H Ji, et al. Non-probabilistic reliability analysis and design optimization for valve-port plate pair of seawater hydraulic pump for underwater apparatus. Ocean Engineering, 2018, 163: 337-347.

[31] L J Yang, S L Nie, S Yin, et al. Numerical and experimental investigation on torque characteristics of seawater hydraulic axial piston motor for underwater tool system. Ocean Engineering, 2015, 104: 168-184.

[32] A Q Zhang, S L Nie, L J Yang. Evaluation of tribological properties on PEEK+CA30 sliding against 17-4PH for water hydraulic axial piston motor. Journal of Mechanical Engineering Science, 2014, 228: 2253-2265.

[33] Y Liu, W Zhang, GX Bu, et al. Study on integration of water vane pump and hydraulic vane motor for a membrane desalination system. Technology of Water Treatment, 2014, 40(4): 52-55.

[34] Y S Liu, D L Li, Z Y Tang, et al. Thermodynamic modeling, simulation and experiments of a water hydraulic piston pump in water hydraulic variable ballast system. Ocean Engineering, 2017, 138: 35-44.

[35] Y S Liu, X J Ren, D F Wu, et al. Simulation and analysis of a seawater hydraulic relief valve in deep-sea environment. Ocean Engineering, 2016, 125: 182-190

[36] Y S Liu, X F Zhao, D F Wu, et al. Study on the control methods of a water hydraulic variable ballast system for submersible vehicles. Ocean Engineering, 2015, 108: 648-661.

[37] F T Barwell. Lubrication of bearings. London: Butterworths Scientific Publications, 1956.

\section{Submit your manuscript to a SpringerOpen ${ }^{\circ}$ journal and benefit from:}

- Convenient online submission

- Rigorous peer review

- Open access: articles freely available online

- High visibility within the field

- Retaining the copyright to your article

Submit your next manuscript at $\boldsymbol{\nabla}$ springeropen.com 